James Branch

Review of Scott McQuire: Geomedia Networked Cities and the Future of Public Space (Cambridge: Polity Press, 2016). ISBN-13: 978-0-7456-6075-2

$£ 45.00$ Hardback £13.99 Paperback

\title{
Learning from Networked Public Space
}

Geomedia by Scott McQuire explores the relationship between media and cities, specifically McQuire is interested in analysing what happens to the theory and practice of urban public space as mobile, embedded media devices, urban screens and extended digital networks become more prevalent. The text contains a historically and theoretically rich account of the entanglement of media and city space, but McQuire stresses his is a less 'mediacentric' mode of analysis. In practice this means he adopts an interdisciplinary approach to his work, taking into account debates from other fields, such as, cultural studies, urban geography and software studies, to name a few. Certainly, his empirical research with artists using large screens for public events, for example, suggests that the book will have appeal across a range of disciplinary boundaries. Readers familiar with McQuire's previous work will be aware of his book, The Media City (2008), that also pursued a non-representational approach, emphasising the active role that contemporary media plays in the production of spaces, practices and experiences within the city. In many ways GeoMedia should be seen as an update and continuation of that volume, but a key difference here is the singular emphasis on urban public space and the focus on learning from artistic interventions in this contested field.

The book shares common ground with publications by Souza e Silva and Frith (2012), Farman (2012) and Berry, Harbord, and Moore (2013) who also explore this intersection of urban public space and media space. However, McQuire has less of a specific focus on mobile media and draws on different theoretical tools. An important driver within the text is the concept of Geomedia, which is developed as a less-, or non-binary way to think about relations between media and face-to-face communication. As McQuire puts it; "Media literally surrounds 
us in urban life, and this state of immersion reconfigures relations between site, boundary and agency across all scales". [15] In this context, he argues, media is not just a record, but contributes to the dynamic elaboration of an event even as it unfolds [56]. Here Geomedia appears to align with the work of Federica Timeto and Richard Coyne who have also analysed art and design interventions to question agency and relations within informational, spatial and social environments. Unfortunately, within the confines of the book, this relational and performative conception of media and space is not given much time to develop. That said, the concept does helpfully describe four contemporary media trajectories; ubiquity, positionality, real-time feedback and convergence. In pulling these strands together, a thought provoking analysis of how power operates through new ways of communicating in the contemporary city is made possible.

What cannot be debated is that the "condition" that Geomedia describes entails some enmeshed and profoundly contradictory outcomes. For McQuire, Geomedia is heavily implicated in 'hyper-industrialization' and instrumental smart city agendas shaping our public spaces. However, at the same time, he argues; "networked public space is today a laboratory for incubating and practising ... new forms of communication, collaboration and cooperative action" [p.16]. Although McQuire warns against posing the future of urban public space as a choice between two easily separable directions, this dichotomy between creeping commercialisation on the one hand, and emergent forms of participation and collaboration on the other, forms the basis of the three case studies that the book hinges upon. A chapter called 'Googling the City', continues McQuire's interest in the imaging of urban space and how this shapes our understanding of the city. In this section the text moves from a discussion of the work of Vertov and Marville, to a critical account of Google Street View and the implications of "data-driven urbanism". The description of the Street View database as an 'operational archive', that is, both a source of information and a means of collecting data about users, is insightful and grounds wider debates about the smart city in a concrete example. 
In the next two chapters, contemporary digital art in public space is the focus of attention, as McQuire sees potential in this field for the emergence of experimental forms of participation and being-with-others in networked public space. In chapter three, Participatory Public Space, Nicolas Bourriaud's (2002) Relational Aesthetics framework and Umberto Eco's (1989) The Open Work are employed to discuss works by Rafael Lozano-Hemmer and the artistic group Blast Theory. McQuire's main argument here is that we can learn from the forms of participation, collaboration and interaction engendered by these digital public artworks, or socio-technical events, and in doing so grasp the complexities of participation in contemporary public space:

By constructing open-ended, participant-driven models of public behaviour, art can help enlarge our current stock of thinking about public space and public culture. The experience of acting together with others to alter the ambience of networked public space enables a different sense of possibility in relation to the city. [121]. These are lofty ambitions and the book doesn't furnish the reader with much detail about how these artworks and experiences might translate into broader shifts in our understanding of public space or public culture. But McQuire is alive to potential criticism throughout the book and suggests that there is value in modest interventions, even if the social impact eludes quantification or scalingup.

A most engaging part of the book, certainly for those coming from a practicebased background, is the fourth chapter, which details the authors' own action research with urban screens and urban media events. Here McQuire draws on previous work in this field to offer a perspective on the emergence of "secondgeneration urban screens" [127] and associated collective experiences or "urban media events". Through first-hand accounts of his work with artists and choreographers on interactive artworks in Australia and Korea, McQuire provides a range of practical insights and references, which students and scholars within media, art and design disciplines will find useful. 
Overall, the book is ambitious and engaging, partly a result of the fast paced movement across a range of concepts, disciplinary boundaries, media objects and sites. However, the text poses as almost as many questions as it answers about the future of public space and the discussion about how we learn from interactive public artworks and apply those learnings to improve our city spaces remains at an embryonic stage. That said, this is an excellent introductory resource for those approaching the vast and multi-faceted topic of public space and it serves as a useful bridge between media scholarship and contemporary art and design practices in an urban public context. The text draws on a vast array of references providing rigorous and approachable overview of some of the key critical theorists in this field.

References

Berry, C., Harbord, J. and Moore, R. eds. (2013). Public Space, Media Space. New York: Palgrave.

de Souza e Silva, A., \& Frith, J. (2012). Mobile interfaces in public spaces: Locational privacy, control, and urban sociability. New York: Routledge.

Farman, J. (2012). Mobile Interface Theory: Embodied Space and Locative Media. London and New York: Routledge.

Biography

James Branch is the Programme Leader of the MA Communication Design course at Winchester School of Art, University of Southampton. He is a founding member of WSAiLab an interaction and prototyping research lab at Winchester. His research interests include: design research, science and technology studies, media theory, critical making and practice-led research. 